\title{
Sequence-specific Polymerase Chain-reaction Markers Derived from Randomly Amplified Polymorphic DNA Markers for Fingerprinting Grape (Vitis) Rootstocks
}

\author{
Hong Xu and Diane J. Wilson \\ Department of Food Science and Technology, Oregon State University, Wiegand Hall, Cowallis, \\ OR 97331-6602
}

S. Arulsekar

Department of Pomology, University of California, Davis, CA 9.5616

\author{
Alan T. Bakalinsky ${ }^{1}$ \\ Department of Food Science and Technology, Oregon State University Wiegand Hall, Corvallis, \\ OR 97331-6602
}

Additional index words. sequence characterized amplified region, SCAR

\begin{abstract}
Randomly amplified polymorphic DNA (RAPD) markers were generated for identifying grape (Vitis) rootstocks. Seventy-seven primers (10 bases long) were screened using CsCl-purified leaf DNA derived from several field samples of nine rootstocks sampled in successive years. Nine RAPD markers were detected from six primers and, in combination, distinguished all nine rootstocks tested. Because inconsistencies were encountered in performing the RAPD assay, sequence-specific primers were derived from cloned RAPD bands for use under more stringent amplification conditions. Southern hybridization analysis of the RAPD gels with cloned RAPD bands as probes revealed deficiencies of scoring RAPD bands based solely on ethidium bromide staining. In some cases, bands of the same size generated by the same primer in different rootstocks-normally scored as the same marker-failed to cross-hybridize, implying lack of homology between the bands. More commonly, bands scored as absent based on ethidium bromide staining were detected by hybridization. Six of the nine cloned RAPD bands were partially sequenced, and sequence-specific primer pairs were synthesized. Two primer pairs amplified a product the same size as the original RAPD band in all rootstocks, resulting in loss of polymorphism. Two other pairs of sequence-specific primers derived from the same marker failed to amplify the expected band consistently. Three of the most useful primer pairs amplified apparent length variants in some accessions and will have value as polymerase chain-reaction markers for fingerprinting.
\end{abstract}

Since the first published description of randomly amplified polymorphic DNA (RAPD) markers, this polymerase chain-reaction (PCR)-based technique has been adopted as a convenient and powerful means of detecting genetic differences among closely related organisms (Welsh and McClelland, 1990; Williams et al., 1990). RAPD markers are generated from genomic DNA under conditions similar to those used in standard PCR, except that a single, short (usually 10 bases long) primer of arbitrary sequence is used at a low annealing temperature. Several loci may be detected per primer and no prior knowledge of target DNA sequence is required. Experimental protocols and genetic applications (Williams et al., 1993) and cautions (Clark and Lanigan, 1993) for RAPD analysis have recently been reviewed.

The RAPD reaction is competitive because the low annealing temperature and short primer presumably permit some mismatches between primer and template (Heun and Helentjaris, 1993). If perfect or near-perfect templates are not present in proper orientation or proximity to permit amplification, less-perfect templates may substitute. This flexibility in priming sequence would account

Received for publication 26 Oct. 1994. Accepted for publication 7 Mar. 1995. Technical paper number 10,522 of the Oregon Agricultural Experiment Station. We thank Theo Dreher, Bryan Ford, and Aaron Liston for comments on the manuscript, Bryan Ford and Rick Bestwick for useful discussions, Xiao Xu, JuWen Wu, and Agritope for technical assistance, and the Oregon-Massachusetts Biotechnology Partnership, the Pacific Northwest Small Fruits Research Center, Agritope, and the Oregon Wine Advisory Board for financial support. The cost of publishing this paper was defrayed in part by the payment of page charges. Under postal regulations, this paper therefore must be hereby marked advertisement solely to indicate this fact.

'To whom reprint requests should be addressed. for the observation that prokaryotic genomes give rise to more RAPD products than would be predicted on the basis of genome size (Williams et al., 1990). Events favoring one or another product in early cycles of PCR may have a far greater effect on the nature and quantity of the final products than under standard conditions, where only a perfect or near-perfect match will be productive.

The competitive aspect of RAPD analysis may explain in part why minor changes in almost any aspect of the amplification reaction have been reported to affect the outcome: DNA quality and quantity (Williams et al., 1993), choice of DNA polymerase (Schierwater and Ender, 1993), Mg concentration (Park and Kohel, 1994; Williams et al., 1993), choice of thermal cycler (Penner et al., 1993), primer concentration (Williams et al., 1993), use of ethidium bromide vs. silver for detection of products (Caetano-Anolles et al., 1992), and presence of RNA (Yoon and Glawe, 1993).

Although some workers have described potential difficulties in using RAPD markers (Ellsworth et al., 1993; Heun and Helentjaris, 1993; Penner et al., 1993; Riedy et al., 1992; Weeden et al., 1992), the present study was undertaken to evaluate their utility for fingerprinting grape (Vitis) rootstocks. Restriction fragment-length polymorphism (RFLP) analyses have revealed genetic differences among grape rootstocks (Bourquin et al., 1991) and cultivars (Bowers et al., 1993; Mauro et al., 1992; Sivolap et al., 1992; Thomas et al., 1993; Yamamoto et al., 1991), but the differences are not yet detectable in a PCR-based assay. In contrast, sequences. flanking grape microsatellites have been developed for use as PCR markers (Thomas and Scott, 1993; Thomas et al., 1994). Although the potential of RAPD markers for fingerprinting grape cultivars has been reported (Collins and Symons, 1993; Jean-Jacques et al., 
1993), Büscher et al. (1993) have expressed reservations. We report here on the generation of RAPD markers to identify grape rootstocks and on the derivation of more reliable PCR markers from them.

\section{Materials and Methods}

Plant material. Rootstocks were sampled from late August through the first week of October 1991, 1992, and 1993 from vineyards at Oregon State Univ. (Woodhall III and the Lewis Brown Farm Mother block) and at Mahonia Nursery, Salem, Ore. Rootstock origins (Galet, 1979) are as follows: MG 420A (Vitis berlandieri x $V$. riparia), Richter 99 ( $V$. berlandieri x $V$. rupestris), $5 C$ ( $V$. berlandieri $\mathrm{x} V$. riparia), $\mathrm{SO} 4(V$. berlandieri x $V$. riparia), Couderc 3309 ( $V$. riparia tomentose $\mathrm{x} V$. rupestris), $\mathrm{MG} 101-14$ (V. riparia $\mathrm{x} V$. rupestris), Couderc 1616 (V. solonis [riparia-rupestris-candicans] x $V$. riparia), Kober 5BB (V. berlandieri selection), and Riparia Gloire (V. riparia selection). Several independent sources of the rootstock SO4 were sampled. Based on isozyme analysis for aspartate aminotransferase (AAT) in our laboratory, two putative SO4 samples (indicated as \#3 or \#3b, and \#14 in the figures) are likely to be 5C (Walker and Boursiquot, 1992).

Grape DNA isolation. Young leaves were held on ice immediately after picking and generally were processed the same day. Leaves were never held for more than 2 days before DNA extraction. Fresh leaves (about $10 \mathrm{~g}$ ) were rinsed in distilled water, frozen, and ground in liquid $\mathrm{N}$.. The powder was suspended in 80 $\mathrm{ml}$ of ice cold extraction buffer [ $0.35 \mathrm{~m}$ sorbitol, $0.1 \mathrm{M}$ Tris, $\mathrm{pH}$ 8.0, $5.0 \mathrm{~mm} \mathrm{MgCl}, 50 \mathrm{~mm} \mathrm{KCl}, 10 \mathrm{~mm}$ EDTA, $10 \mathrm{~mm}$ sodium sulfite, $10 \mathrm{~mm}$ 2-mercaptoethanol, 1\% polyvinylpyrrolidone-40 (PVP-40, Sigma Chemical Co., St. Louis)] and blended at high speed in a prechilled blender. The blended leaf extract was poured through cheesecloth and centrifuged at $10,000 \times \mathrm{g}$ for $15 \mathrm{~min}$ at $4 \mathrm{C}$. The supernatant was discarded and the pellet gently suspended in $8 \mathrm{ml}$ of $50 \mathrm{~mm}$ Tris, $10 \mathrm{~mm}$ EDTA $(\mathrm{pH} 8.0)$ by mixing before $10 \mathrm{~g}$ of $\mathrm{CsCl}, 800 \mu \mathrm{l}$ of $10 \% \mathrm{SDS}$, and $200 \mu \mathrm{l}$ of $100 \%$ Triton $\mathrm{X}-100$ were added. The tubes were covered, mixed, and held at $55 \mathrm{C}$ for $15 \mathrm{~min}$ before centrifugation as before. The liquid fraction was transferred to a clean tube with minimal disturbance of the starch grain precipitate at the bottom or the plug of cell debris at the top of the tube. Ethidium bromide (11 drops of a $5-\mathrm{mg} \cdot \mathrm{ml}^{-1}$ solution) was added, and the solution was held at room temperature in the dark until being subjected to standard equilibrium centrifugation
(Maniatis et al., 1982). DNA stocks were stored in TE at -20C. Dilutions for PCR were prepared as needed in distilled water and held at 4C. Concentrations were estimated by comparing the fluorescence of electrophoretically mobile high-molecular-weight DNA to known amounts of lambda phage DNA in a minigel stained with ethidium bromide.

Oligonucleotide primers. RAPD primers were obtained from Operon Technologies (OP) (Alameda, Calif.) and from the Univ. of British Columbia (UBC). The sequences of primers found to identify polymorphisms are (5' to $3^{\prime}$ ') as follows: OPG02, (GGCACTGAGG); OPG05, (CTGAGACGGA); OPG06, (GTGCCTAACC); UBC204, (TTCGGGCCGT); UBC231, (AGGGAGTTCC); and UBC251, (CTTGACGGGG).

Sequence-specific primers (Table 1) were synthesized at the Central Services Laboratory of the Oregon State Univ. Center for Gene Research and Biotechnology. The primers were designed by adding 10 to 14 bases to the 3' end of the original 10-mers to amplify sequence characterized amplified regions (SCARs) as described by Paran and Michelmore (1993), except where sequence analysis indicated potential interfering interactions between or within primers (Table 1). In the latter cases, primers were designed to minimize interfering interactions (i.e., false priming and stable interand intra-primer duplexes), without regard to whether the terminal sequences were retained (Williamson et al., 1994).

$R A P D$ reactions. Reaction mixtures in $50 \mathrm{~mm}$ Tris $-\mathrm{HCl}, 20 \mathrm{~mm}$ $\left(\mathrm{NH}_{4}\right)_{2} \mathrm{~S} \mathrm{O}_{4}(\mathrm{pH} 9.0)$ contained 1 unit of $T f l$ DNA polymerase (Epicentre Technologies, Madison, Wis.); $100 \mu \mathrm{M}$ each of dATP, dTTP, dCTP, and dGTP; $0.2 \mu \mathrm{M}$ primer; $1.5 \mathrm{~mm} \mathrm{MgCl}$; and about 2.5 or $5 \mathrm{ng}$ genomic DNA in a final volume of 12.5 or $25 \mu \mathrm{l}$, respectively. Reaction mixtures were overlaid with mineral oil (E.R. Squibb \& Sons, Princeton, N.J.) in an Ericomp thermal cycler (EasyCycler; Ericomp, San Diego) and heated for $5 \mathrm{~min}$ at $94 \mathrm{C}$, followed by 40 cycles of $30 \mathrm{sec}$ at $94 \mathrm{C}, 1 \mathrm{~min}$ at $35 \mathrm{C}$, and 2 $\min$ at $72 \mathrm{C}$; followed by a final $5 \mathrm{~min}$ at $72 \mathrm{C}$. Slightly different conditions were used in the Perkin-Elmer thermal cycler (PerkinElmer Corp., Norwalk, Conn.): $10 \mathrm{~mm}$ Tris-HCl (pH 8.3); $50 \mathrm{~mm}$ $\mathrm{KCl} ; 1.9 \mathrm{~mm} \mathrm{MgCl}$; $0.001 \%$ gelatin; $100 \mu \mathrm{m}$ each of dATP, dTTP, $\mathrm{dCTP}$, and dGTP; $0.2 \mu \mathrm{M}$ primer; and 1 unit of AmpliTaq DNA polymerase (Perkin-Elmer Corp.), and about 5 to $10 \mathrm{ng}$ genomic DNA in a final volume of $25 \mu \mathrm{l}$. Reaction mixtures were overlaid with mineral oil and heated for $2 \mathrm{~min}$ at $94 \mathrm{C}$, followed by 45 cycles of $1 \mathrm{~min}$ at $92 \mathrm{C}, 1 \mathrm{~min}$ at $35 \mathrm{C}$, and $2 \mathrm{~min}$ at $72 \mathrm{C}$; followed by 1 cycle at $72 \mathrm{C}$ for $5 \mathrm{~min}$.

Table 1. Sequence-specific primer pairs derived from cloned RAPD bands.

\begin{tabular}{|c|c|c|}
\hline Primer pair ${ }^{2}$ & & Annealing temp $\left({ }^{\circ} \mathrm{C}\right)$ \\
\hline $\mathrm{OPG02U}_{860}$ & $5^{\prime}$-GGC ACT GAG GCA ACA CAT AA-3' & 47 \\
\hline OPG02L $\mathrm{L}_{860}$ & $5^{\prime}$-CTG AGG ATA ATC TTG TGC AA-3' & \\
\hline OPG05U & 5'-CTG AGA CGG AGA GCT AAA AAA TAA-3' & 47 \\
\hline OPG05L $\mathrm{L}_{550}$ & 5'-CTG AGA CGG ACA CTA TTT CAC ACA-3' & \\
\hline $\mathrm{UBC}_{204 \mathrm{U}_{1140}}$ & 5'-TTC GGG CCG TGT CAC ATG AAT TCC-3' & 55 \\
\hline UBC $204 L_{1140}$ & 5'-TTC GGG CCG TTG ACT TTG AGG CAA-3' & \\
\hline $\mathrm{UBC}_{231 \mathrm{U} 1_{1840}}$ & 5'-AGG GAG TTC CGG TCA CTT GTT TCT-3' & 49 \\
\hline UBC231L $1_{1840}^{1840}$ & $5^{\prime}$ - $\underline{\text { GG GAG TTC C }} \wedge \wedge \mathrm{C} \Lambda \Lambda \mathrm{G} \wedge \mathrm{T}$ TT $\Lambda \wedge$ GT-3' & \\
\hline UBC231U2 & 5’-ACC GGT ATG GTA CAG ATG CT-3' & 49 \\
\hline UBC231L2 & 5'-GGG AGT TCC AAC AAG ATT TA-3' & \\
\hline $\mathrm{UBC}_{231 \mathrm{U}_{1660}}$ & 5'-TCC ACG GAC GGG TTG GGA TAG ATT-3' & 55 \\
\hline UBC $231 L_{1660}^{1000}$ & 5'-TCC ACG GAC GAA TTC CAG GGG GTC-3' & \\
\hline $\mathrm{UBC} 51 \mathrm{U}_{1440}$ & 5'-CTT GAC GGG GTA TGC TGG GCT GAG-3' & 53 \\
\hline $\mathrm{UBC}_{251 \mathrm{~L}_{1440}}$ & 5'-CTT GAC GGG GGA GGG TTT GAA-3' & \\
\hline
\end{tabular}


After amplification, about one-fourth of each reaction was electrophoresed in a $1.5 \%$ agarose gel in TAE buffer at 4 to $5.3 \mathrm{~V} /$ $\mathrm{cm}$. A 123-bp DNA ladder served as molecular weight markers (Gibco, BRL, Gaithersburg, Md.). The gels were stained with ethidium bromide, and the banding patterns were viewed and photographed on a UV transilluminator.

All reaction mixtures were prepared in a laminar flow hood, and control reactions containing all components except genomic DNA were performed with each set of amplifications. If a potentially polymorphic band was generated in the control reaction, the experiment was repeated. In general, the control reactions yielded no products or yielded products that had no counterparts in any of the experimental reactions.

Reproducibility of RAPD bands. RAPD bands were considered reproducible if they were observed in at least two separate amplifications from DNA isolated in multiple years when $T f l$ D N A polymerase was used in the Ericomp thermal cycler, without regard to the total number of amplifications attempted, nor to the reproducibility of other bands on the same gels. The RAPD marker-grape rootstock matrix (Table 2) is based on these $T f l$ amplifications. RAPD bands generated using AmpliTaq in the Perkin-Elmer thermal cycler were considered reproducible if they were observed in at least two different amplifications from single DNA isolations, without regard to the total number of attempts nor to the reproducibility of other bands. RAPD bands that are informative in distinguishing grape rootstocks are referred to as RAPD markers only in the context of band phenotype because their inheritance is unknown.

Sequence-specific amplifications. Amplifications involving sequence-specific primers were conducted in either the Ericomp or Coy thermal cycler (model 50 TempCycler; Coy Laboratory Products, Ann Arbor, Mich.). The thermal cycling was the same as indicated for the RAPD reactions above except 1) 30 instead of 40 cycles were used and 2) annealing temperatures (Table 1) were chosen based on an optimization analysis of the primer sequences using Oligo version 4.0 (National Biosciences, Plymouth, Minn.).

Cloning and sequencing RAPD markers. Tfl DNA polymerasegenerated RAPD bands excised from agarose gels and purified using a Geneclean kit (Bio 101, La Jolla, Calif.) were cloned into pCRI1 (Invitrogen Corp., San Diego) and introduced into competent E. coli INVaF' according the supplier's instructions. Recombinants were identified as white or pale blue colonies on $\mathrm{X}$-gal medium. Plasmid DNA was isolated from several independent transformants by alkaline lysis using the rapid procedure of Zhou et al. (1990) or Magic Minipreps (Promega Corp., Madison, Wis.). Putative positive transformants, based on the size of insert DNA, were confirmed by labeling the cloned inserts and using them to probe Southern blots of the original RAPD gels. Restriction enzymes were used according to the manufacturer's instructions, U.S. Biochemical Corp. (Cleveland) or Boehringer Mannheim (Indianapolis). Southern transfers were performed using Zeta-Probe membranes (Bio-Rad Laboratories, Richmond, Calif.) and alkaline transfer as described by the manufacturer. Hybridizations at $65 \mathrm{C}$ and random primed DNA labeling were done using the Genius System according to the manufacturer's instructions (Boehringer Mannheim). Digoxigenin-labelled DNA was detected by chemiluminescence. The cloned RAPD markers were subjected to dideoxy sequencing using T7 and SP6 sequencing primers.

Aspartate aminotransferase isozymes. AAT (EC 2.6.1.1) isozymes from dormant cambial tissue (Subden et al., 1987) were examined according to the procedures of Arulsekar and Parfitt (1986) and staining solution modifications described in Walker and Boursiquot (1992).

\section{Results}

DNA isolation. Yields of grape DNA were low, ranging from 10 to $20 \mu \mathrm{g} \cdot \mathrm{g}^{-1}$ fresh tissue. All DNA isolated was amplifiable under RAPD conditions and, in the few instances where genomic DNA was digested with restriction enzymes, inhibition was not apparent. The rationale for using a relatively lengthy $\mathrm{CsCl}$-based procedure for DNA extraction was that DNA of the highest quality was desired. Because nanogram amounts are sufficient for RAPD amplifications, obtaining high yields was not an important consideration.

Generation of RAPD markers. Only three of the 77 RAPD primers tested failed to produce amplification products. The rest produced at least five resolvable bands and often many more, ranging from 400 to 2500 bp from most rootstocks. Bands were scored conservatively; thus, a large number of potentially polymorphic products were eliminated from consideration. These included relatively faint bands, and bands that were prominent in some rootstocks but barely visible rather than absent in others. Nine RAPD markers, i.e., informative bands, were generated from six RAPD primers that together distinguished all the rootstocks (Table 2).

Failed amplifications were of three sorts: reactions that pro-

Table 2. Rootstock-RAPD marker matrix.

\begin{tabular}{|c|c|c|c|c|c|c|c|c|c|}
\hline \multirow[b]{2}{*}{ Rootstock } & \multicolumn{9}{|c|}{ RAPD marker ${ }^{2}$} \\
\hline & $\mathrm{OPG} 2_{860}$ & $\mathrm{OPG} 02_{1320}$ & $\mathrm{OPG}_{550}$ & $\mathrm{OPG} 05_{1420}$ & $\mathrm{UBC}^{20} 4_{1140}$ & $\mathrm{UBC}_{231_{1840}}$ & UBC231 1660 & $\mathrm{UBC}_{25} 1_{1440}$ & OPG06 $_{1440}$ \\
\hline$\overline{\mathrm{MG} \mathrm{420A}}$ & + & & & + & + & & & + & + \\
\hline Richter 99 & + & + & & & + & + & + & & + \\
\hline $5 C^{y}$ & + & & & & & & + & & + \\
\hline SO4 \#4 & + & & & & + & & + & & + \\
\hline SO4 \#12 & + & & & & + & & + & & + \\
\hline Riparia Gloire & $?$ & & & & & & & & \\
\hline Couderc 3309 & & & & $?$ & + & & & + & + \\
\hline MG 101-14 & & & & + & & & $?$ & & \\
\hline Kober 5BB & $?$ & & $?$ & & & & $?$ & & + \\
\hline Couderc 1616 & & & & & + & & & & + \\
\hline
\end{tabular}

$\overline{2}(+)$ The presence of the indicated marker when rootstock DNA was used in an appropriate DNA amplification reaction. (?) An ambiguous result. The number and letters preceeding the subscript (size of RAPD marker in bp) refer to the primer used to generate the marker. OP $=\mathrm{Operon}$; UBC $=\mathrm{Univ}$. of British Columbia.

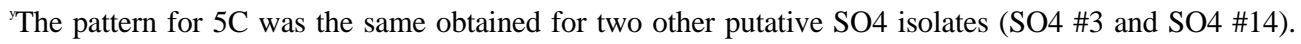


Table 3. Hybridization analysis of cloned RAPD bands.

\begin{tabular}{|c|c|c|c|}
\hline Marker & False negatives & False positives & Other hybridizing bands \\
\hline$\overline{\mathrm{OPG} 02_{860}}$ & No & No & Yes \\
\hline OPG02 & Yes & No & Yes \\
\hline $\mathrm{OPG}^{1} 5_{550}^{1320}$ & No & No & Yes \\
\hline UBC204 & No & Yes & Yes \\
\hline $\mathrm{UBC} 231_{1840}^{1140}$ & No & No & Yes \\
\hline $\mathrm{UBC} 234_{922}$ & Yes & No & Yes \\
\hline $\mathrm{UBC} 231_{1660}$ & No & No & Yes \\
\hline UBC251 & No & No & Yes \\
\hline $\mathrm{OPGO6}_{1440}$ & No & Yes & Yes \\
\hline
\end{tabular}

$\overline{{ }^{2} \text { RAPD gels were blotted and probed with individual cloned RAPD bands. Hybridizations were interpreted relative to expectations }}$ based on positive or negative scoring of the RAPD bands on the original ethidium bromide-stained gels. False negative $=$ a hybridization signal was observed when the band was not seen on the RAPD gel; false positive = no hybridization signal or a substantially weaker one was observed when the putative band was seen on the RAPD gel. Other hybridizing bands = presence of hybridizing bands other than the expected RAPD band.

duced 1) no products, 2) smears instead of discrete bands, and 3) faint discrete bands. Generally, for every successful amplification, one to two attempts were made. Using fresh DNA dilutions, new mineral oil, and new buffer did not noticeably improve these

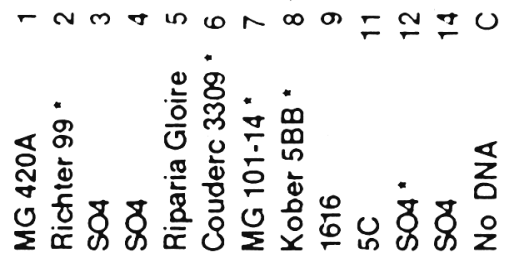

922 bp

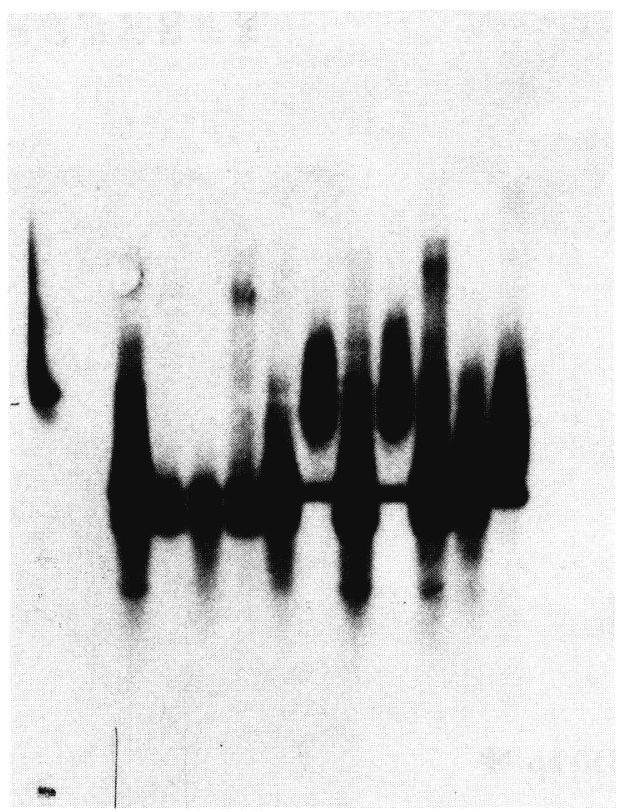

Fig. 1. Hybridization of cloned RAPD band UBC234 $4_{922}($ arrow) to a Southern blot of the RAPD gel. Rootstocks marked with asterisks had been scored positive for the marker. Because the intact recombinant vector was labeled and used as a probe, the hybridization signal in the unmarked first lane, containing the 123-bp molecular weight ladder, reflects homology between vector sequences and the 123-mer. Based on their isozyme (AAT) profiles, the rootstocks designated SO4 $\# 3$ and \#14 are likely 5C. amplifications. However, a systematic effort to determine the basis for the failed reactions was not undertaken. More often than not, the expected amplification was restored on repeating the assay without deliberate alteration in protocol.

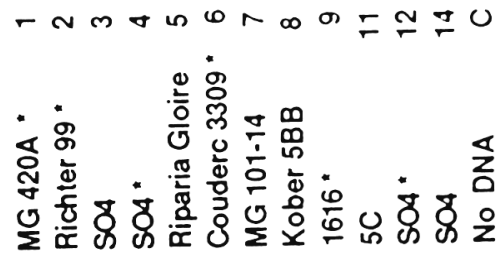

$1,140 \mathrm{bp}$

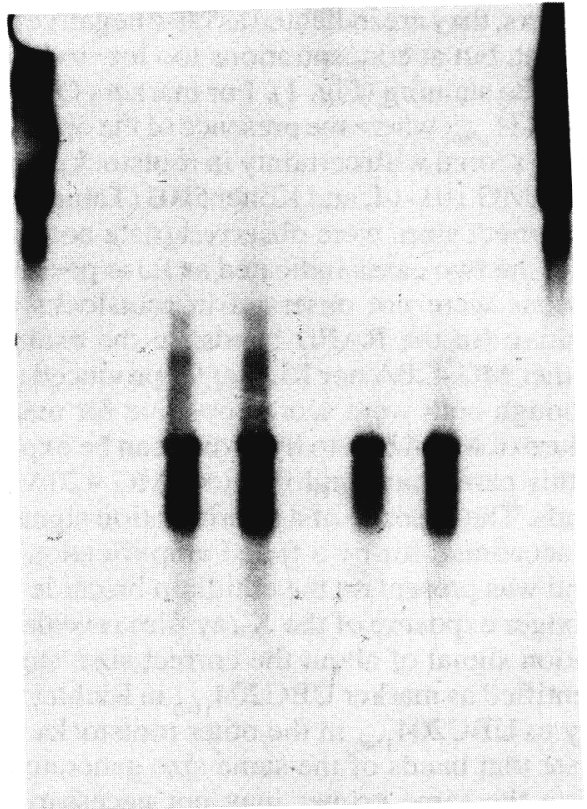

Fig. 2. Hybridization of cloned RAPD band UBC204 ${ }_{1140}$ (arrow) to a Southern blot of the RAPD gel. Rootstocks marked with asterisks had been scored positive for the marker. On this particular gel, the amplification with MG 420A produced no discrete bands. Because the intact recombinant vector was labeled and used as a probe, the hybridization signal in the unmarked outer lanes, containing the 123bp molecular weight ladder, reflects homology between vector sequences and the 123-mer. SO4 \#3 and \#14 are likely 5C; refer to Fig. 1 legend. 
An experiment was performed to determine if AmpliTaq used in a Perkin-Elmer thermal cycler would produce the same RAPD products obtained with $T f l$ DNA polymerase in an Ericomp thermal cycler. The three Operon primers-OPG02, OPG05, and OPG06-used with AmpliTaq produced banding patterns that contained new polymorphic bands but that-bore no resemblance to those observed using $T f l$ (data not shown). The minor differences in cycling parameters were in the total number of cycles (40 vs. 45), the lengths of the initial denaturation and final extension steps (5 vs. of $2 \mathrm{~min}$ at $94 \mathrm{C}$ and $5 \mathrm{vs}$. of $1 \mathrm{~min}$ at 72C), and in the temperature and time used for the repeated denaturation step (30 set at $94 \mathrm{C}$ vs. $1 \mathrm{~min}$ at 92C). While it is possible that these differences may account for the different products, dependence of RAPD bands on the DNA polymerase used has been noted in grapes (Büscher et al., 1993), corn (Williams et al., 1993), and in a crustacean (Schierwater and Ender, 1993). A third heat-stable DNA polymerase (Replitherm, Epicentre Technologies) used in buffer supplied by the manufacturer failed to generate RAPD products under the PCR conditions used for $T f l$ (data not shown).

Because we did not determine the causes of the failed reactions and wanted an assay that did not depend on a particular heat-stable DNA polymerase, we decided to design sequence-specific PCR primers from the RAPDs that could be used under more-stringent amplification conditions (Paran and Michelmore, 1993). Thus, we cloned the nine informative RAPD bands and designed primers for the six that were sequenced.

Southern hybridization analysis of cloned RAPD markers. Confirmation that the correct bands had been cloned was based on I probing blotted RAPD gels with the cloned markers and comparing the hybridization patterns with the banding patterns based on 1 ethidium bromide staining (Table 3 ). In all cases, hybridizing; bands in addition to the expected RAPD bands were observed. When hybridization signals corresponding to the RAPD markers were observed in rootstocks that had been scored as lacking the markers, they are indicated as false negatives because the bands are present, but at concentrations too low to be detected by ethidium bromide staining (Fig. 1). For markers OPG02 $2_{860}$, OPG05 ${ }_{1420}$, and UBC2 $31_{1660}$, where the presence of the original RAPD bands could not be scored with certainty in rootstocks Riparia Gloire, Couderc 3309, MG 101-14, and Kober 5BB (Table 2), hybridizing bands of the correct sizes were observed (data not shown).

In the two cases indicated as false positives (Table 3), hybridizations were not observed in rootstocks that had been scored positive for the RAPD bands. In the example shown in Fig. 2, neither MG 420A nor Richter 99 produced a hybridization signal, although both were scored positive for marker UBC204 $4_{1140}$. The failure of MG 420A to hybridize can be explained by the fact that, in this particular amplification, MG 420A produced no discrete bands. The absence of a hybridization signal in Richter 99 cannot be accounted for by a failed amplification because the expected band was present on the ethidium bromide stained gel. However, a longer exposure of the X-ray film revealed a very weak hybridization signal of about the correct size, suggesting that the band identified as marker UBC204 $4_{1140}$ in Richter 99 shares poor homology to UBC204 $4_{1140}$ in the other rootstocks. These results demonstrate that bands of the same size generated in different samples using the same primer may not necessarily represent the same sequence, although such bands are typically scored as the same RAPD marker.

Figure 3 shows an example of specific detection of the expected marker OPG05 $5_{55}$ in the only rootstock that produced it, Kober 5BB. A slightly larger cross-hybridizing band is also seen. Interestingly, because $\mathrm{OPG} 05_{550}$ could no longer be detected by ethidium bromide staining in the third year of the study, an uncertain score for Kober $5 \mathrm{BB}$ is indicated in the rootstock-RAPD marker matrix (Table 2).

Amplifications using sequence-specific primers. Six of the RAPD markers were partially sequenced and seven new sequencespecific primers were synthesized for use under more stringent amplification conditions. The most useful primer pairsOPG02 $\mathrm{U}_{860}$ and OPG02 $\mathrm{L}_{860}$ (Fig. 4), OPGO5 $\mathrm{U}_{550}$ and OPG05L $\mathrm{L}_{550}$, and $\mathrm{UBC}_{2} 31 \mathrm{U}_{1660}$ and $\mathrm{UBC}_{2} 31 \mathrm{~L}_{1660}$-generated additional bands that may represent length variants. Southern blots of gels based on amplifications with the first two primer pairs with cloned markers $\mathrm{OPG} 02_{860}$ and $\mathrm{OPG} 05_{550}$, respectively, revealed that the additional bands were homologous to the original markers (data not shown). Southern analysis was not performed on the amplifications with primer pair $\mathrm{UBC} 31 \mathrm{U}_{1660}$ and $\mathrm{UBC} 231 \mathrm{~L}_{1660}$.

Amplifications involving sequence-specific primer pairs $\mathrm{UBC} 204 \mathrm{U}_{1140}$ and $\mathrm{UBC} 204 \mathrm{~L}_{1140}$ and $\mathrm{UBC} 51 \mathrm{U}_{1440}$ and $\mathrm{UBC}^{251 \mathrm{~L}_{1440}}$ resulted in a loss of polymorphism because all rootstocks gave rise to the formerly polymorphic RAPD bands. Although rootstocks 5C and SO4 are polymorphic for RAPD marker UBC204 $4_{140}$, (Table 2), postamplification digestions of the product generated by primer

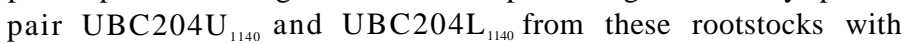
Bam HI, Eco RI, Hin dIII, Pst I, Xba I, Hae III, and Sau IIIAI failed to

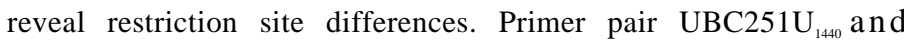
UBC $251 \mathrm{~L}_{1440}$ amplified other products in addition to the monomorphic band. Using higher- and lower-than-optimal annealing temperatures with this primer pair, or lower-than-optimal tem-
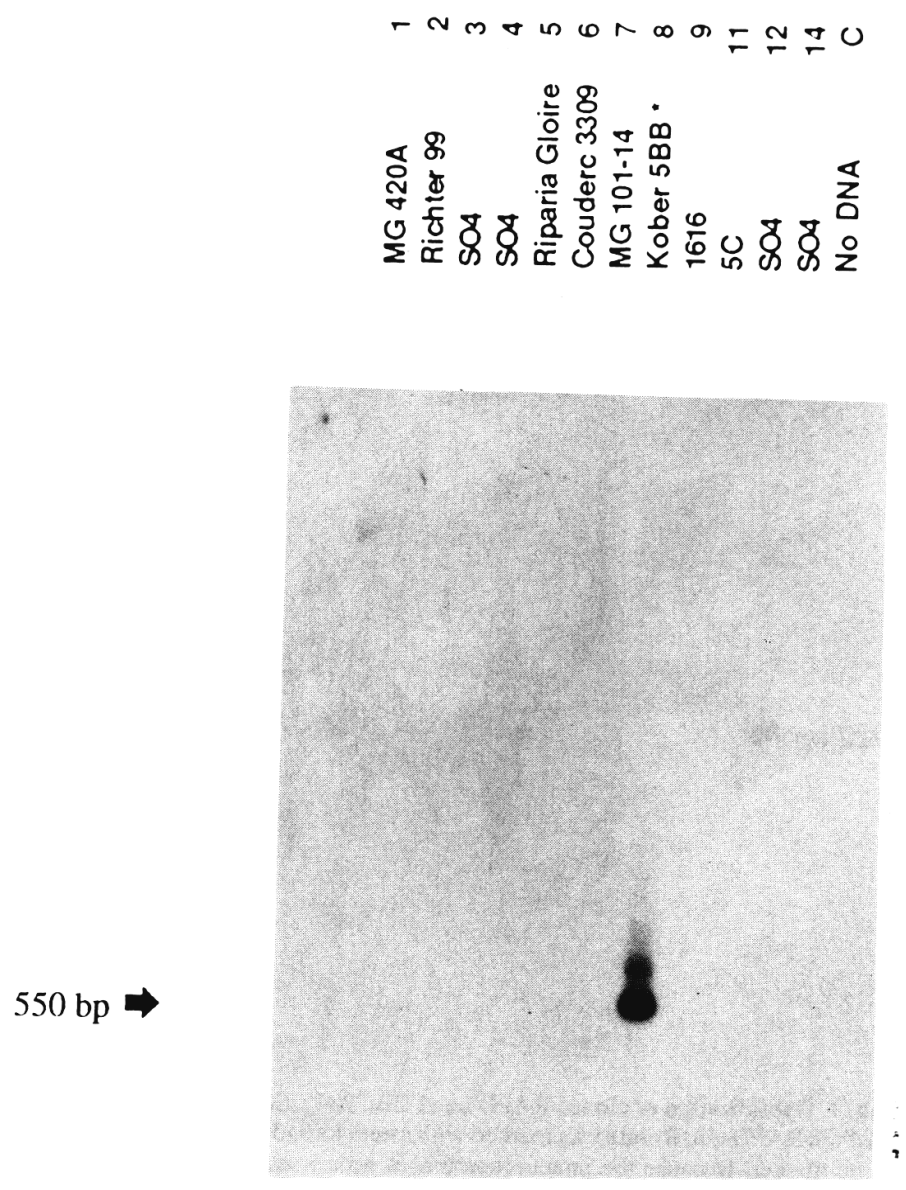

Fig. 3. Hybridization of cloned RAPD band OPG05 (arrow) to a Southern blot of the RAPD gel. Only Kober 5BB (asterisk) had been scored positive for the marker. SO4 \#3 and \#14 are likely 5C; refer to Fig. 1 legend. 
peratures with $\mathrm{UBC} 204 \mathrm{U}_{1140}$ and $\mathrm{UBC} 04 \mathrm{~L}_{1140}$, did not result in -amplification of length variants (restoration of polymorphism). For unknown reasons, neither of the two pairs of sequence-specific primers designed from cloned marker UBC231 ${ }_{1840}$ amplified the expected product consistently. Certain primers have been observed to amplify poorly, or not at all from sequences that lack obvious potential secondary structure (Innis, 1990). Using higherand lower-than-optimal annealing temperatures with primer pair $\mathrm{UBC} 231 \mathrm{U} 1_{1840}$ and $\mathrm{UBC} 231 \mathrm{~L}_{1184}$ did not restore polymorphism.

\section{Discussion}

Inconsistencies in results of RAPD reactions made the RAPD markers less useful than desired. To improve their utility, six of the nine cloned markers were partially sequenced, and sequencespecific primer pairs were synthesized. Two amplified a product the same size as the original RAPD band in all rootstocks, resulting in loss of polymorphism. Two other pairs of sequence-specific primers designed from the same cloned RAPD band failed to amplify the expected bands consistently. However, three of the primer pairs amplified apparent length variants from some accessions and will have value as PCR markers for fingerprinting.

Although RAPD markers were generated for fingerprinting grape rootstocks, the inconsistencies we encountered in performing the amplifications made the procedure impractical. For markers to have value in fingerprinting, they must be reliable, practical, and validated in independent laboratories (Smith and Smith 1992), especially if they are to be used in cultivar patent disclosures and in legal cases of varietal infringement. The sensitivity of the RAPD reaction to various reaction parameters may demand a degree of standardization that is difficult to sustain even within a laboratory, let alone between laboratories.

Three of seven sequence-specific primer pairs derived from the cloned informative RAPD bands were reliable and useful because

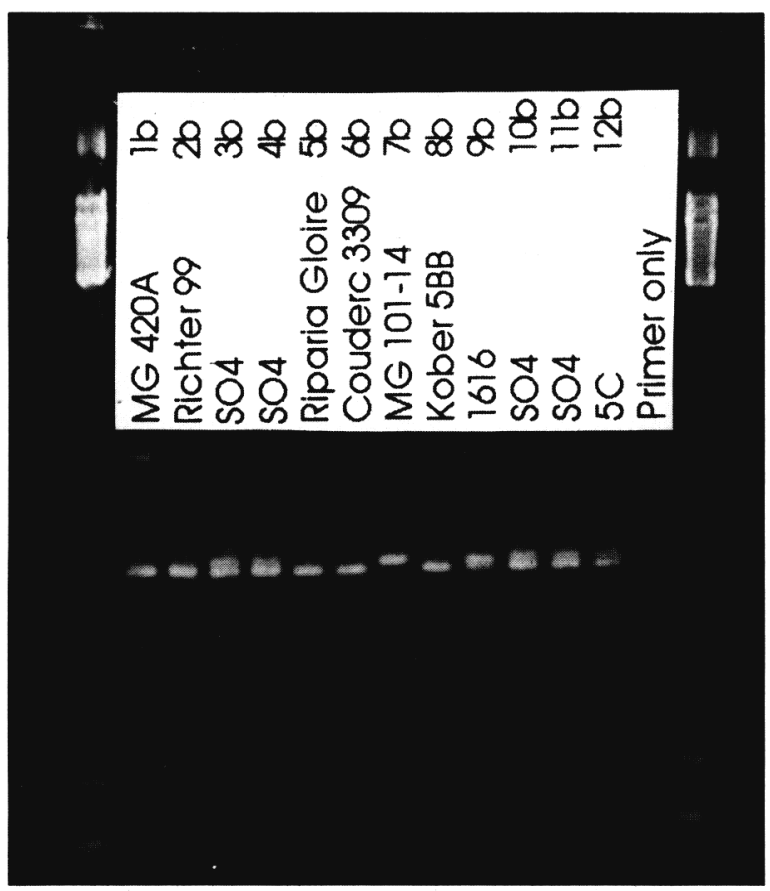

Fig. 4. Amplification products obtained with sequence-specific primers $O P G O 2 \mathrm{U}_{860}$ and OPG02 $\mathrm{L}_{860}$. The lower of the two bands was expected, the upper is an apparent length variant. The outer lanes consist of a 123-bp molecular weight ladder. SO4 \#3b is likely 5C; refer to Fig. 1 legend. they amplified apparent length variants in addition to the expected products. Although Southern analysis established homology among the variants in the two cases tested, it is not possible to establish allelism in the absence of a pedigree. Paran and Michelmore (1993) reported that eight of nine RAPD-derived sequence-specific primers amplified the original polymorphic product or new alleles among segregating populations of lettuce.

Results from the Southern analysis showed lack of homology among some amplified bands of the same size generated with the same 10-mer primers in different rootstocks. It is important to point out that various Vitis species are often used as rootstocks for grape scion cultivars and that most of them are of interspecific hybrid origin. Weeden et al. (1992) correctly noted that, without detailed genetic, DNA hybridization, or DNA sequence analysis, it is extremely difficult to establish that RAPD bands amplified in individuals of undefined relationship are homologous. This is a major impediment to using RAPD bands to fingerprint distantly related cultivars.

Without knowing the source of the polymorphisms that produced the RAPD bands, one cannot predict whether simple extension of the 10-mers to make longer sequence-specific primers will retain them. In the present study, half of the attempts were successful. One interpretation of why two of the primer pairs amplified the same product in all rootstocks is that the original polymorphism is in the sequences to which the RAPD primer anneals. The rootstocks that failed to amplify the RAPD band may have had poor matches at one or both termini. Adding 10 to 14 bases to the 3' terminus of the 10-mer primers in anonpolymorphic region may have provided enough homology to overcome the original mismatch and to permit annealing and amplification. Alternatively, an insertion between primer binding sites might have increased the size of the product beyond the range of the PCR conditions applied. This latter possibility would account for lack of a product when the original 10-mer was used. However, in this case, extension of the 10-mers would not be expected to result in the observed amplification.

Our ongoing efforts to sequence regions in the grape genome to which the RAPD primers anneal will provide the evidence needed to assess the importance of primer-template mismatches and may also permit more rational design of RAPD-derived primers such that the original or newly discovered polymorphisms are retained.

\section{Literature Cited}

Arulsekar, S. and D.E. Parfitt. 1986. Isozyme analysis procedures of stone fruits, almond, grape, walnut, pistachio and fig. HortScience 21:928933.

Bourquin, J-C, L. Otten, and B. Walter. 1991. Identification of grapevine root-stocks by RPLP. C.R. Acad. Sci. Paris 312:593-598.

Bowers, J.E., E.B. Bandman, and C.P. Meredith. 1993. DNA fingerprint characterization of some wine grape cultivars. Amer. J. Enol. Viticult. 44:266-274.

Büscher, N., E. Zyprian., and R. Blaich. 1993. Identification of grapevine cultivars by DNA analyses: pitfalls of random amplified polymorphic DNA techniques using 10mer primers. Vitis 32:187-188.

Caetano-Anollés, G., B.J. Bassam, and P.M. Gresshoff. 1992. DNA amplification fingerprinting with very short primers. 1992. Proc. Symp. Appl. RAPD Tech. Plant Breeding. Joint Plant Breeding Symp. Ser., 1 Nov. 1992. Minneapolis. p. 18-25.

Clark, A.G. and C.M.S. Lanigan. 1993. Prospects for estimating nucleotide divergence with RAPDs. Mol. Biol. Evol. 10:1096-1111.

Collins, G.G. and R.H. Symons. 1993. Polymorphisms in grapevine DNA detected by the RAPD PCR technique. Plant Mol. Biol. Rpt. 11:105112.

Ellsworth, D.L., K.D. Rittenhouse, and R.L. Honeycutt. 1993. Artifactual 
variation in randomly amplified polymorphic DNA banding patterns. BioTechniques 14:214-217.

Galet, P. 1979. A Practical Ampelography. Cornell Univ. Press, Ithaca, N.Y.

Heun, M. and T. Helentjaris. 1993. Inheritance of RAPDs in F, hybrids of corn. Theor. Appl. Genet. 85:961-968.

Innis, M.A. 1990. PCR with 7-deaza-2'-deoxyguanosine triphosphate, p. 54-59. In: M.A. Innis, D.H. Gelfand, J.J. Sninsky, and T.J. White (eds.). PCR protocols: A guide to methods and applications. Academic Press, New York.

Jean-Jacques, I., A. Defontaine, and J.N. Hallet. 1993. Characterization of Vitis vinifera cultivars by random amplified polymorphic DNA markers. Vitis 32:189-190.

Maniatis, T., E.F. Fritsch, and J. Sambrook. 1982. Molecular cloning, a laboratory manual. Cold Spring Harbor Laboratory Press, Cold Spring Harbor, N.Y.

Mauro, M.-C., M. Strefeler, N.F. Weeden, and B.I. Reisch. 1992. Genetic analysis of restriction fragment length polymorphisms in Vitis. J. Hered. 83:18-21.

Paran, I. and R.W. Michelmore. 1993. Development of reliable PCRbased markers linked to downy mildew resistance genes in lettuce. Theor. Appl. Genet. 85:985-993.

Park, Y.-H. and R.J. Kohel. 1994. Effect of concentration of $\mathrm{MgCl}_{2}$ on random-amplified DNA polymorphism. BioTechniques 16:652-656.

Penner, G.A., A. Bush, R. Wise, W. Kim, L. Domier, K. Kasha, A. Laroche, G. Stoles, S.J. Molnar, and G. Fedak. 1993. Reproducibility of random amplified polymorphic DNA (RAPD) analysis among laboratories. PCR Meth. Appl. 2:341-345.

Riedy, M.F., W.J. Hamilton III, and C.F. Aquadro. 1992. Excess of nonparental bands in offspring from known primate pedigrees assayed using RAPD PCR. Nucleic Acid Res. 20:918.

Schierwater, B. and A. Ender. 1993. Different thermostable DNA polymerases may amplify different RAPD products. Nucleic Acid Res. 21:4647-4648

Sivolap, Y.M., T.G. Verbitskaya, and S.N. Prokopenko. 1992. Investigation of intraspecies DNA polymorphism in the grape Vitis vinifera. Cytol. Genet. 26:10-16.

Smith, J.S.C. and O.S. Smith. 1992. Fingerprinting crop varieties. Adv. Agron. 47:85-141.
Subden, R.E., A. Krizus, S.C. Lougheed, and K. Carey. 1987. Isozyme characterization of Vitis species and some cultivars. Amer. J. Enol. Viticult. 38:176-181.

Thomas, M.R., P. Cain, and N.S. Scott. 1994. DNA typing of grapevines: A universal methodology and database for describing cultivars and evaluating genetic relatedness. Plant Mol. Biol 25:939-949.

Thomas, M.R., S. Matsumoto, P. Cain, and N.S. Scott. 1993. Repetitive DNA of grapevine: Classes present and sequences suitable for cultivar identification. Theor. Appl. Genet. 86:173-180.

Thomas, M.R. and N.S. Scott. 1993. Microsatellite repeats in grapevine reveal DNA polymorphisms when analyzed as sequence-tagged sites (STSs) Theor. Appl. Genet. 86:985-990.

Walker, M.A., and J.M. Boursiquot. 1992. Ampelographic and isozyme data correcting the misnaming of the grape rootstock SO4 at the University of California, Davis. Amer. J. Enol. Viticult. 43:261-265.

Weeden, N.F., G.M. Timmerman, M. Hemmat, B.E. Kneen, and M.A. Lodhi. 1992. Inheritance and reliability of RAPD markers. Proc. Symp. Appl. RAPD Tech. Plant Breeding. Joint Plant Breeding Symp. Ser., 1 Nov. 1992, Minneapolis. p. 12-17.

Welsh, J. and M. McClelland. 1990. Fingerprinting genomes using PCR with arbitrary primers. Nucleic Acid Res. 189:7213-7218.

Williams, J.G.K., A.R.K. Kubelik, J.L. Livak, J.A. Rafalski, and S.V. Tingey. 1990. DNA polymorphisms amplified by random primers are useful as genetic markers. Nucleic Acid Res. 18:6531-6535.

Williams, J.G.K., M.K. Hanafey, J.A. Rafalski, and S.V. Tingey. 1993. Genetic analysis using random amplified polymorphic DNA markers, $p$. 704-740. In: R. Wu (ed.). Methods in enzymology. vol. 218. Academic Press, New York.

Williamson, V.M., J.-Y. Ho, F.F. Wu, N. Miller, and I. Kaloshian. 1994. A PCR-based marker tightly linked to the nematode resistance gene, $\mathrm{Mi}$, in tomato. Theor. Appl. Genet. 87:757-763.

Yamamoto, N., G. Ono, K. Takashima, and A. Totsuka. 1991. Restriction fragment length polymorphisms of grapevine DNA with phenylalanine ammonia-lyase cDNA. Jpn. J. Breed. 41:365-368.

Yoon, C.-S. and D.A. Glawe. 1993. Pretreatment with RNase to improve PCR amplification of DNA using 10-mer primers. BioTechniques 14:908-910.

Zhou, C., Y. Yang, and A.Y. Jong. 1990. Mini-prep in ten minutes. BioTechniques 8:172-173. 